\title{
SYNTHESIS, CHARACTERIZATION AND PHOTOLUMINESCENCEPROPERTIES OF NEW COUMARIN HYDRAZIDE AND ITS LANTHANIDE (III) COMPLEXES
}

\author{
Badr A. Elsayed*, Ibrahem A. Ibrahem, Salah M. Shaaban and Mohamed M. Elsenety
}

Department of Chemistry*, Faculty of Science, Al-Azhar University, Nasr City, Cairo, Egypt, P.O. 11823

\begin{abstract}
A novel coumarin hydrazide ligand derived from the condensation of 7-hydroxy coumarin-4-ethylacetate with salicylaldehyde hydrazone and its complexes with Sm(III) and Eu(III) have been synthesized. The ligand and its complexes have been characterized by the Elemental analysis, Molar conductivity, FTIR, IHNMR, and U.V. \& Visible spectra. The complexes have stoichiometry of the type $\left[\mathrm{Ln}(\mathrm{L})_{2}\left(\mathrm{H}_{2} \mathrm{O}\right)_{2}\right] \mathrm{NO}_{3} \cdot 2 \mathrm{H}_{2} \mathrm{O}$ where the ligand $(\mathrm{HL})$ coordinates to the lanthanide ions $\mathrm{Sm}(\mathrm{III})$ and/or Eu(III) through azomethine nitrogen atom, phenolic oxygen of hydrazide moiety after deprotonation and ketonic oxygen of coumarin moiety. The fluorescence properties of complexes in different organic solvents (DMSO, DMF, Acetonitrile and Ethanol) have been studied. A strong red fluorescence of europium complex was observed and was attributed to the ligand energy transfers to the energy level of Eu(III).

Keywords: Coumarin hydrazide, Lanthanide complexes, photoluminescence properties.
\end{abstract}

\section{INTRODUCTION:}

In the past decades many fluorescence dyes such as coumarin derivatives have been developed to label bimolecular compounds [1]. In particular, fluorescent dye materials exhibit fluorescence emission at a longer wavelengths in the red light region play essential role in full color electroluminescence displays [2]. Because of these dyes have absorption and emission wavelength in UV-visible region, biological matrix exhibits highabsorption and auto-fluorescence background [1]. Fluorescence dyes are used in potential application such as industry (paint, inks, and cosmetics), medicine, agriculture and textile [3-5].Fluorescence dye probe is used to detect the structures of RNA and DNA, study the remedy of DNA damaged basic group, identify the status of amino group and the active area of protein molecule, detect protein in pool scalar, distinguish nucleic acids with different conformation and the chemical reactive activities of related drugs [6]. They are widely used as fluorescent labels and pigments, as fluorescent probes for physiological and enzymatic measurements, as signaling units in sensors and in sophisticated photophysical systems [7, 8]. Coumarin derivatives and their lanthanide complexes have attracted much interest owing to their potential application in organic lightemitting diodes (OLED's) [9-11]. They provide enzyme substrates for fluorometric titrations in biomedical analysis [12]. Some complexes of trivalent lanthanide ions have attracted considerable attention because of their distinguished luminescent properties, especially $\mathrm{Eu}(\mathrm{III}), \mathrm{Tb}(\mathrm{III})$ and Sm(III) complexes which are emissive in the visible region of the spectrum $(400-800 \mathrm{~nm})$ [1318]. Lanthanide complexes such as of the present work have attracted a great deal of interest in recent years because they have applications as antioxidant [19], in medicinal inorganic chemistry [20,21], catalysis [22], luminescence chemical probes and sensors [23] and pharmacological activities [24].

\section{EXPERIMENTAL:}

\section{Materials:}

All the chemicals used in the present work were of reagent grade and used without further purification. $\mathrm{Eu}\left(\mathrm{NO}_{3}\right)_{3} \cdot 5 \mathrm{H}_{2} \mathrm{O}$ and $\mathrm{Sm}\left(\mathrm{NO}_{3}\right)_{3} \cdot 6 \mathrm{H}_{2} \mathrm{O}$ (Sigma Aldrich, purity, 99.9\%).Organic solvents absolute ethanol, acetonitrile, dimethylformamide (DMF) and dimethylsulfoxide(DMSO) were of reagent grade and used withoutfurther purification.

Citric acid monohydrate, Resorcinol, Sulfuric acid, Thionil chloride (SOCl2),Hydrazine monohydrate (98\%), Salicylaldelydewere of reagent grade and were used without further purification. 


\section{SpectralMeasurements:}

\section{IR spectra}

The Infrared (IR) spectra of the ligand and its Lanthanide(III)complexes were recorded on a IR 200 spectrometerthermoelectron in the 4000$400 \mathrm{~cm}-1$ region as aKBr disks.

\section{Electronic spectra}

The Ultraviolet and Visible absorption spectra of the ligand and its complexes were recorded in DMSO solventusing a PERKIN-ELMER UVspectrophotometer in the region of 200-800 nm.

\section{Fluorescence spectra}

All luminescence measurements were recorded in a quartz cuvette $(10 \mathrm{~mm} \times 10 \mathrm{~mm})$, using a Thermo Fisher Scientific spectrofluorophotometer with emission slit width of $5 \mathrm{~nm}$. (190-900 nm).

\section{$1 H N M R$}

The proton 1HMR spectrumof theligandwas measured on a Varian $300 \mathrm{MHz}$ Spectrometer in deuterateddimethylsulphoxide (d6-DMSO) solvent using tetramethylsilane (TMS) as internal reference and the chemical shifts were expressed in ppm.

\section{Thermal analysis}

TGA/DTA were measured from room temperature to $800^{\circ} \mathrm{C}$ at a heating rate of $10^{\circ} \mathrm{C} / \mathrm{min}$. The data were obtained by using a PERKIN-ELMERDIAMOND instrument.

\section{Microanalytical analysis}

Carbon, hydrogen and nitrogen analysis of the ligand and its complexeshave been carried out in Vario EL Fab. CHNS Nr. 11042023.

\section{Molar conductance}

The molar conductances of $10^{-4} \mathrm{M}$ solutions of the ligand and its metal complexes in DMSO solvent weremeasured on a $\mathrm{HACH}$ conductimetermodel. All the measurements were taken at room temperature for freshly preparedsolutions.

2.3 Synthesis of the ligand andits lanthanide complexes

2.3.1 Synthesis of the ligand (HL): a. Synthesis of 2-(7-hydroxy-2-oxo-2H-chromen-4-yl) acetic acid(I)

A mixture of citric acid monohydrate ( 0.1 mole) and $28 \mathrm{ml}$ of concentrated sulphuric acid was stirred at room temperature for $1 \mathrm{hr}$, and then slowly heated to $70^{\circ} \mathrm{C}$, the mixture was heated with stirring to half an hour throughout, the evolution of carbon monoxide had slackened and the clear yellow colored solution was rapidly cooled to $0^{\circ} \mathrm{C}$. To this stirred solution, were added resorcinol (0.08 mole) and $11.2 \mathrm{ml}$ of concentrated sulphuric acid on three equal portions, at a rate that the temperature does not exceed $10^{\circ} \mathrm{C}$.

The resulting product was stored at $0 \mathrm{oC}$ for sixteen hours, after that waspoured into ice and the resulting crystalline white precipitate was filtered off and washed thoroughly with distilled water. It was thentreated with $200 \mathrm{ml}$ sodium bicarbonate $10 \%(\mathrm{w} / \mathrm{v})$ and then filtered[25]. The filtrate acidified by adding $133 \mathrm{ml} \mathrm{HCl} 10 \%$ (v/v) until its $\mathrm{pH}$ value reached to 1.43 , then the product washed with distilled water, and dried in oven. (Yield 79\%, M.P $205^{\circ} \mathrm{C}$ )

b. Synthesis of ethyl 2-(7-hydroxy2-oxo-2H-chromen-4-yl) acetate (II) The substituted coumarin-4-acetic acid (1 mol) was dissolved in ethanol $(100 \mathrm{ml})$, and a few drops of catalyticthionyl chloride were added. The reaction mixture was refluxed with heating for $6 \mathrm{hrs}$. After the completion of the reaction, ethanol was evaporated and the resulting product (II) was extracted with ethyl acetate, after removing the unreacting $\mathrm{SOCl}_{2}$, then the product washed with sodium bicarbonate, and dried in oven. The solvent was removed to give thecompound(II).(Yield 85\%, M.P 135 $\left.{ }^{\circ} \mathrm{C}\right)[26]$.

c. Synthesis of the salicylaldehydehydrazon e(III)

The salicyladehyehydrazone ( $\mathrm{SH}$ ) was prepared according to the previous method [27]. (Yield $81 \%$, M.P $98^{\circ} \mathrm{C}$ )

d. Synthesisof coumarin ligand(HL)

Add (4.996g,100 mmol) of salicylaldehydehydrazone, in $100 \mathrm{ml}$ absolute ethanol drop wise with stirring to coumarin-4-acetic ethylacetate 
<smiles>CCCCCCOC(=O)Cc1cc(=O)oc2cc(O)ccc12</smiles>

(II)
(III)<smiles>O=C(Cc1cc(=O)oc2cc(O)ccc12)N/N=C/c1ccccc1O</smiles>

(TV)

\section{Scheme (1): Reaction of prepared Ligand (HL}

$(12.212 \mathrm{~g}, 100 \mathrm{mmol})$ in $100 \mathrm{ml}$ absolute ethanol in $250 \mathrm{ml}$ round flask. The mixture was heated to reflux for 12 hour. The formed solid product was left to coagulate overnight, then filtered off and recrystallized from absolute ethanol.

The Reaction of the prepared ligand (IV) was shown in Scheme (1) and its analytical data in Table(1).

e.Synthesis of Eu (III) and Sm(III) complexes:

$\mathrm{Sm}(\mathrm{III})$ and $\mathrm{Eu}$ (III) complexes of the ligand (HL) were synthesized as follow:Europium (III) nitratepentahy drate $\mathrm{Eu}\left(\mathrm{NO}_{3}\right)_{3} .5 \mathrm{H}_{2} \mathrm{O}$ or $\mathrm{Sm}$ (III) nitrate hexahydrateSm $\left(\mathrm{NO}_{3}\right)_{3} \cdot 6 \mathrm{H}_{2} \mathrm{O}(0.0005 \mathrm{~mol})$ dissolved in ethanol. The ligand $(0.001 \mathrm{~mol})$ dissolved in the absolute ethanol and $0.1 \mathrm{mlfrom}$ triethanolamin was added to the solution of
$\mathrm{Eu}\left(\mathrm{NO}_{3}\right)_{3} \cdot 5 \mathrm{H}_{2} \mathrm{O}$ or $\mathrm{Sm}\left(\mathrm{NO}_{3}\right)_{3} \cdot 6 \mathrm{H}_{2} \mathrm{Owith}$ constant stirring and was further refluxed for $6 \mathrm{hr}$. The mixture solution was then concentrated to a small volume until the product obtained.Then filtered washed with absolute ethanoland dried under room temperature overnight.

The reaction of the prepared complex (V) is shown in Scheme (2) and its analytical data in Table(1).

\section{RESULTS AND DISCUSSION}

\subsection{Properties of the complexes}

Analytical data for the complexes, presented in Table (1), with the chemical formula $\left[\mathrm{Ln}(\mathrm{L})_{2}\left(\mathrm{H}_{2} \mathrm{O}\right)_{2}\right] \mathrm{NO}_{3} \cdot 2 \mathrm{H}_{2} \mathrm{O} \quad \mathrm{Ln}=\mathrm{Eu}(\mathrm{III})$ or $\mathrm{Sm}(\mathrm{III})$.

All of the complexes are soluble in DMSO<smiles>O=C(Cc1cc(=O)oc2cc(O)ccc12)N/N=C/c1ccccc1O</smiles>

$\mathrm{Eu}\left(\mathrm{NO}_{3}\right)_{3} .5 \mathrm{H}_{2} \mathrm{O}$

$+\quad$ or

$$
\operatorname{Sm}\left(\mathrm{NO}_{3}\right)_{3} .6 \mathrm{H}_{2} \mathrm{O}
$$

(TV)

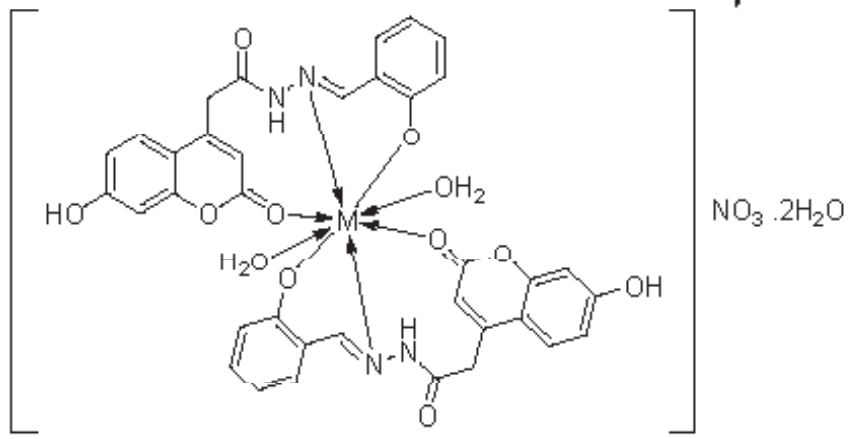

Schema (2): Reaction of prepared Ln(III)-Complexes
(M) $M=E u^{\prime \prime \prime}$

(V) $M=S m^{\prime \prime \prime}$ 
and DMF, slightly soluble in ethanol, insoluble in water and benzene.

Conductance measurement data for the synthesized complexes in DMSO solution were shown in Table (1) indicatedthat the two complexes 2:1 (L/M) were ionic compounds[28].

\subsection{IR spectra}

The IR band assignments of the coumarin ligand (HL) and $\mathrm{Ln}(\mathrm{III})$ complexes are given in Table(2) and spectra of the ligand and its Sm(III) and $\mathrm{Eu}(\mathrm{III})$ complexes are shown in Fig.(1). The IR spectra of the two complexes are similar. The IR spectra of $\mathrm{Ln}$ (III) complexes showed the vibrational bands characterized the free ligand with the appropriate shifts due to complex formation but for the spectra of the two complexes displayed similarity.

The IR band at $1541 \mathrm{~cm}^{-1}$ of free coumarin ligand(HL) was attributed to the presenceof azomethine group. This band was shifted to lower wavenumber by $70 \mathrm{~cm}^{-1}$ due to the complexation [29]indicating a stronger double bond character of the imine band and a coordination of the azomethinenitrogenatom to $\operatorname{Ln}(\mathrm{III})$ ion[30-32]. This coordination was confirmed by the appearance of non-ligand medium intensity band around $\left(586,585 \mathrm{~cm}^{-1}\right)$ of $v(\mathrm{Ln}-\mathrm{N})$ vibrational.

The spectrum of the ligand exhibits a broad band at $3359 \mathrm{~cm}^{-1}$, which was assigned to the

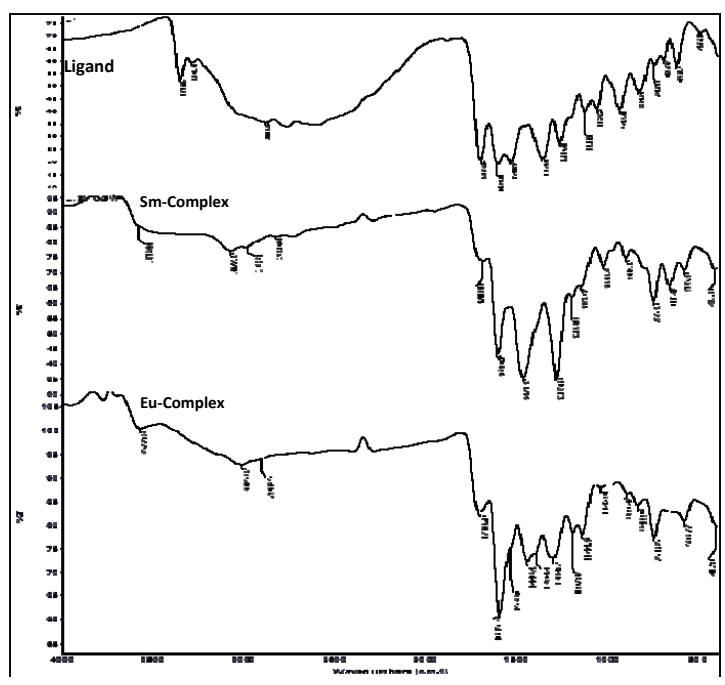

Figure 1: FTIR spectra of the ligand and its Sm(III) and $\mathrm{Eu}(\mathrm{III})$ Complexes stretching vibration of aromatic hydroxyl substituent and 7-hydroxyl substituent of coumarin moiety. The disappearance of aromatic hydroxyl group after complex formation was attributed to the coordination through the phenolic-OH was confirmed by the new medium intensity band appeared around $413 \mathrm{~cm}^{-1}(\mathrm{Eu}(\mathrm{III}))$ and $412 \mathrm{~cm}^{-1}(\mathrm{Sm}(\mathrm{III}))$ complexes assigned to $v(\mathrm{Ln}$ O)vibrational[29]. The complexes show six absorption bands around 1471, 1285, 1030, 907, 755 and $665 \mathrm{~cm}-1$ which assigned respectively to $v 4 v 1 v 2 v 6 v 3$ and $v 6$ vibrations [33].

\subsection{Electronic spectra}

The UV-Vis absorption spectra of under investigated ligand and its $\mathrm{Ln}$ (III) complexes were measured in DMSO solution at room temperature. The observed electronic transition bands associated with the ligand and its Ln(III) complexes $(\mathrm{Eu}(\mathrm{III}) \& \mathrm{Sm}(\mathrm{III}))$ werecollected in Table (3). The spectrum of the ligand (HL) showed five main characteristic absorption bands in the regions $202-370 \mathrm{~nm}$. The bands at the $\lambda \max =202,215$ and 236 were assigned to $\pi$ à $\pi^{*}$ transition states [32]. The bands at 298 and 331 were attributed to the $\pi$ à $\pi^{*}$ transition states of the azomethin group and the $\lambda \max 331$ and 370 $\mathrm{nm}$ were attributed to $\mathrm{n}$ à $\pi^{*}$ transition states of the azomethine nitrogen atom and the nonbonding electrons on the oxygen atoms as well the intra-molecular charge transfer[32]. The U.V.Vis. absorption spectra of the $\operatorname{Ln}(\mathrm{III})$ coumarin complexes were identical, with similar structures and showed most of the characteristic bands associated with the free ligand with some shifts for the characteristic bands due to the complexation to longer wavelength(red shift) compared to the free ligand as shown in Table (3). These shifts and intensities of the absorption bands associated with complexes confirmed the coordination of the ligand to the metal ion. It is well known that, the lanthanide ions have no absorption bands in their complexes, due to the $\mathrm{f}-\mathrm{f}$ transitions are laporte-forbidden and very weak in nature [34].

\subsection{H NMR studies}

$1 \mathrm{H}$ NMR spectrum of the coumarin ligand (HL) was recorded in DMSO-d6 in the presence of TMS as internal standards. The ligand has the 
Synthesis, characterization and photoluminescenceproperties

following signals $\sigma(\mathrm{ppm}): 3.6\left(2 \mathrm{H}, \mathrm{CH}_{2}\right.$ group), $7.5(1 \mathrm{H}, \mathrm{CH}$ group $), 6.10(\mathrm{H},-\mathrm{CH}=$ in $\mathrm{C} 3$ of coumarin moiety), $7.8(1 \mathrm{H}, \mathrm{NH}$ group $), 3.4(1 \mathrm{H}, \mathrm{Ar}-$ $\mathrm{OH}), 3.51(1 \mathrm{H}, \mathrm{OH}$-coumarin moiety) and 6.2-7.5 $\mathrm{ppm}$ are assigned to the proton of both phenolic and coumarin moiety[35,36].

\subsection{Thermal analysis of the Eu(III)complex}

The DTA curve of the Eu(III)complex reveal seven steps in the sequential decomposition of the coumarin europium complex over the experimental temperature range $\left(25-800^{\circ} \mathrm{C}\right)$ which determined for all steps in the decomposition sequence as long as it's DTA curve showed a maximal rate of mass loss. Mechanism of the thermal decomposition process of the complex under investigation could be investigated as follow: five successive degradation steps have been occurred at 40-80, 220-225, 300-305, 420-440 and $455-7500 \mathrm{C}$. The mass loss at (40-80 0C) of $3.72 \%$ equivalent to the evolution of two uncoordinated water molecules (Cal. 3.75\%) with weak exothermic (Tdta). The mass loss at (220-225 $0 \mathrm{C})$ of $3.85 \%$ indicated two coordinated water molecules (Cal. 3.75). The one nitrate group was eliminated with mass lose $6.72 \%$ at (300-3050C) as an endothermic peak. The mass lose at (420$4400 \mathrm{C}$ ) of $71.60 \%$ identified the decomposition of two coumarin moieties of the complex. At the end of decomposition process at (455-750 0C) the final residue which is undefined state may be
EuO with mass loss (17.5\%).

3.6Photophysical properties of the Ligandand itsLn(III) complexes:

a.Study of the fluorescence spectra of the ligand in different solvents:

The fluorescence excitation and emission spectra of the ligand in the different solvent DMSO, AC, EtOH and DMF were shown in Fig. (2).

The emission bands associated with the ligand indifferent solventsat excitation wavelength 340 $\mathrm{nm}$ show a maximum emission bands around 461, 397, 404 and $404 \mathrm{~nm}$ using DMSO, Ac, EtOH and DMF solventsrespectively, which were attributed to $\pi^{*}$ à $\pi$ electronic transition with a shift of $\Delta V \operatorname{Vst}(73-130 \mathrm{~nm})$ from their $\lambda$ ex depending on their polarity indexes.

The magnitudes of stokes shift wereattributed to the charge transfer transitions, where the large magnitudes of stokes shift indicated that the excited-state geometry could be different from that of the ground-state. The general observation visualized is that there is an increase in the stokes shift values with increasing solvent polarity and an increase in the dipole moment on excitation.

The fluorescence quantum yield (Qf) were calculated by preparing solutions of the $(1 \times 10-$ $4 \mathrm{M}$ ), measuring theirabsorbance and fined their

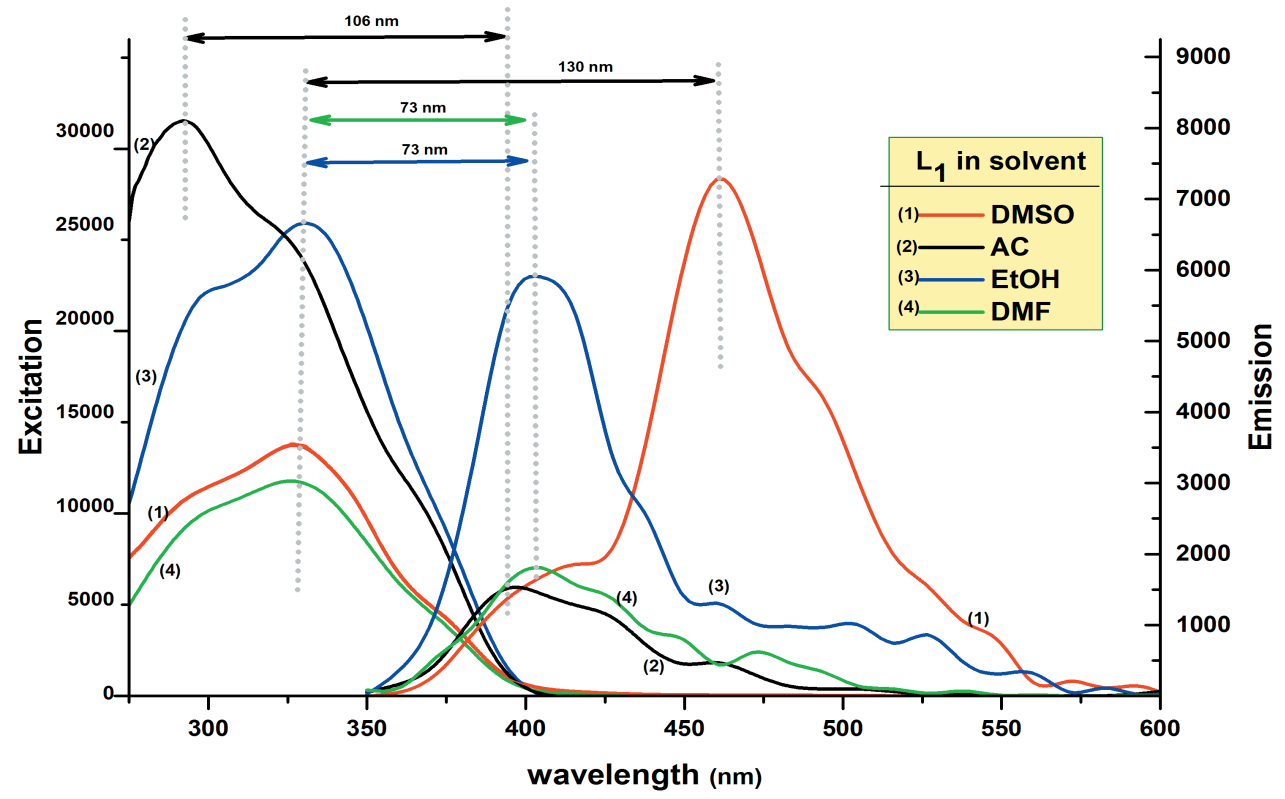

Figure 2: Excitation and Emission spectra of the ligand in different solvents 


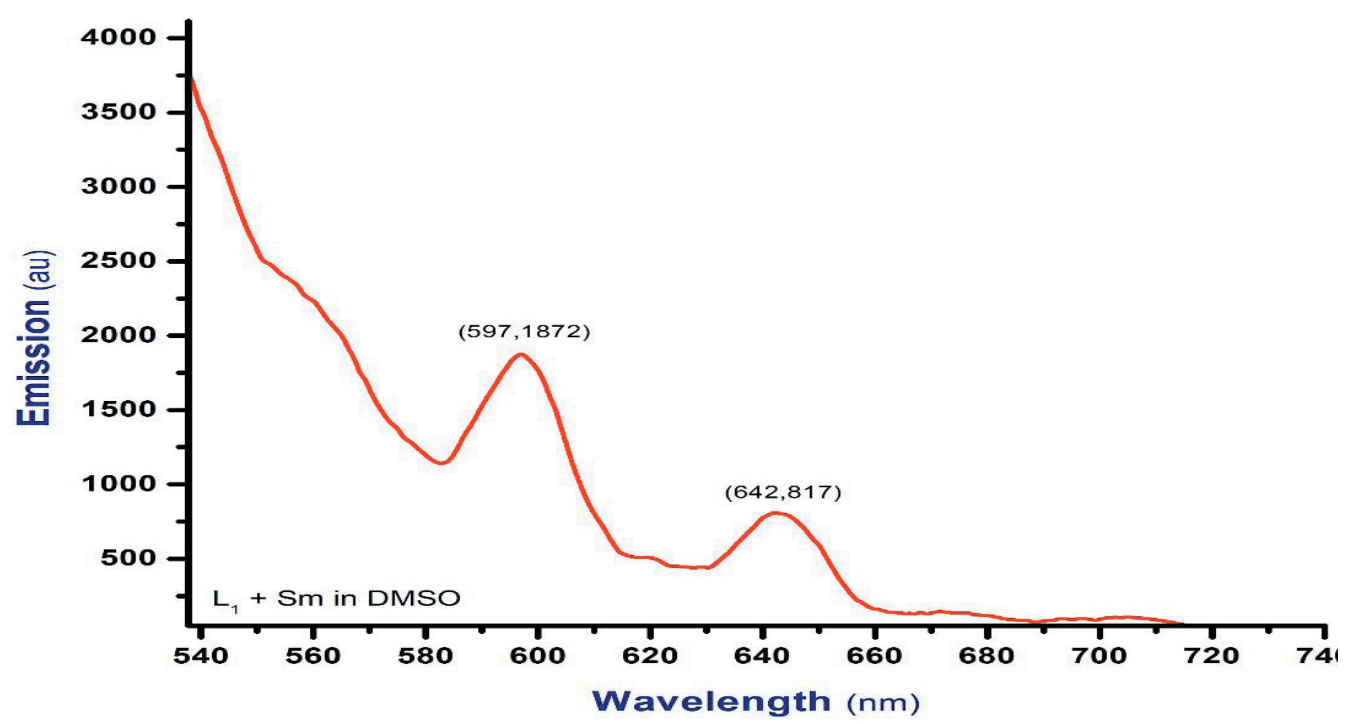

Figure 4: Fluorescence spectra of $\mathrm{Sm}$ complex in DMSO

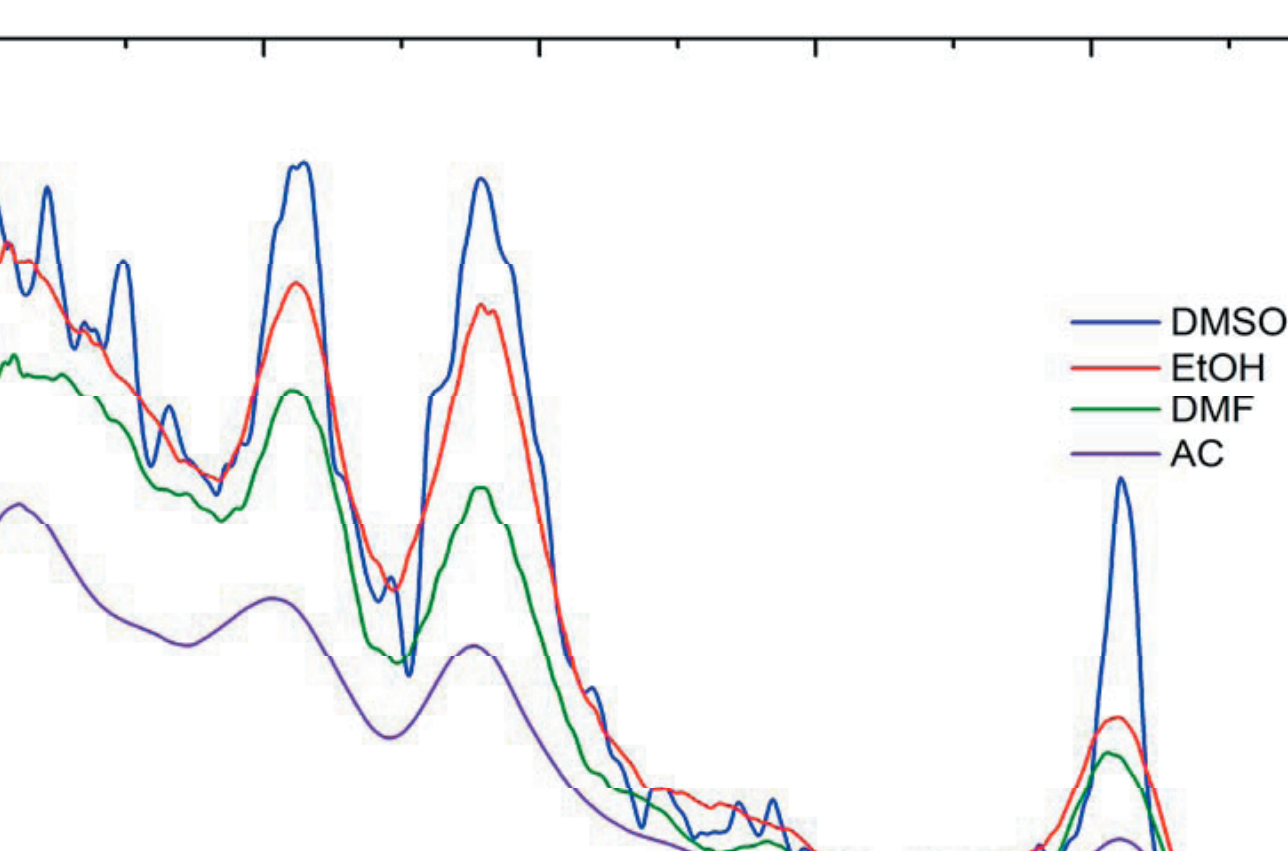

Figure 4: Fluorescence spectra of Eu complex in different solvents

area under the emission peaksfor each solvent. The absorbance and the area were compared to a reference fluorescence quantum yield (quinine sulphate)[37]. The data were collected in Table(4).

From the obtained data the fluorescence quantum yield of the Ligand in different solventswere calculated using the following equation[38]:

$$
\begin{aligned}
& \mathrm{Qf}=\mathrm{Qs}(\mathrm{F} / \mathrm{Fs})(\mathrm{As} / \mathrm{A})(\eta 2 / \eta \mathrm{s} 2) \\
& \mathrm{Qf}=\text { fluorescence quantum yield, }
\end{aligned}
$$

Qs=Quantum yield of reference, $\mathrm{F}=$ area under the fluorescence emission curve of sample, Fs= area under the fluorescence emission curve of reference, $\mathrm{A}=\mathrm{Absorbance}$ of sample, $\mathrm{As}=\mathrm{Ab}$ sorbance of reference, $\eta=$ refractive index of sample, $\eta \mathrm{s}=$ refractive index of reference.Here Quinine Sulphate was used as reference, which has a quantum yield of 0.546 when dissolved in $(0.5 \mathrm{M}) \mathrm{H} 2 \mathrm{SO} 4$ had a refractive index of 1.346.

$b$. Study of the fluorescence spectra of the lanthanide complexes in different solvents: 
The effect of the solvents on the fluorescence intensities of the Eu and Sm complexes were studied in (DMSO, AC, EtOH, and DMF) solvents. Thephotoluminescence spectralbands associated with Sm-complexat excitation wave length $380 \mathrm{~nm}$ Fig.(3)were Obscured in Ac, EtOH, and DMF while were appeared in DMSO at (561, $597,642,685) \mathrm{nm}$ which attributed to $(4 \mathrm{G} 5 / 2$ à6H5/2, 4G5/2 à6H7/2, 4G5/2 à6H9/2,4G5/2 à6H11/2electronictransitions)respectively. On the otherhand the photo spectral bands of EucomplexFig.(4)were appeared at (572, 588, $618,650,699) \mathrm{nm}$ in (DMSO, AC, EtOH, and DMF) solventsrespectively, which attributed to (5D0à7F0, 5D0à7F1, 5D0à7F2,5D0à7F3, 5D0à 7F4electronictransitions)respectively.

\section{Conclusion:}

A systematic study of the structural and photoluminescence properties of $\mathrm{Sm}$ (III) and $\mathrm{Eu}$ (III) complexes with4-(2-hyroxybenzylideneacetohydrazide)-7-hydroxy coumarin anion was carried out. The structures of $\left[\mathrm{Ln}(\mathrm{L}) 2\left(\mathrm{H}_{2} \mathrm{O}\right)_{2}\right] \mathrm{NO}_{3} \cdot 2 \mathrm{H}_{2} \mathrm{O}$, $\mathrm{Ln}=\mathrm{Sm}(\mathrm{III})$ or/and $\mathrm{Eu}(\mathrm{III})$ revealed that two ligand molecules were coordinated as tridentate for each via the oxygen of phenolic-OH, ketonic oxygen of coumarin moiety, and the nitrogen of azomethine group while two water molecules coordinated to central $\mathrm{Ln}$ (III) which mean, coordination number eight was suggested for the metal ion in these lanthanide(III) nitrate complexes. As well another two uncoordinated water molecules were bound in the outer coordination sphere in complexes. The fluorescence data exhibit characteristic luminescence of Sm(III) and $\mathrm{Eu}(\mathrm{III})$ ions, which revealed the role of organic moiety chelator to absorb and transfer energy to $\mathrm{Sm}(\mathrm{III})$ and $\mathrm{Eu}(\mathrm{III})$ ions.

\section{REFERENCES}

[1] F.Song, X.Peng, E.Lu, R.Zhang, X.Chen and B.Song, J. Photochemistry and Photobiology A: chemistry 168 (2004) 53-57.

[2] E.Horiguchi, K.Shiraia, M.Matsuoka, and M.Matsui, J. Dyes and Pigments 53 (2002) 45-53.

[3] G. Bardajee, A. Li, J. Haley and M. Winnik, J. Dyes and Pigments, 79(1) (2008) 24-32.

[4] S.Um, J. Dyes and Pigments 75 (2007) 185-188.

[5] C.Sahoo, A. Gupta and A.Pal, J. Dyes and Pigments 66 (2005) 189-196.
[6] X. Fei and Y.Gu, J. Progress in Natural Science 19 (2009) 1-7.

[7] R. Chistie, K. Morgan and M. Islam, J. Dyes and Pigments 76(2008) 741-747.

[8] A. Jagtap, V. Satam, R. Rajule and V. Kanetkar, J. Dyes and Pigments 82 (2009) 84-89.

[9] Yu T., Zhao Y., Ding X., Fan D., Qian L. and Dong W., J.Photochemistry and Photobiology A: chemistry 188 (2007) 245-251.

[10] V. Bekiari and P. Lianos, Adv. Mater. 12 (2000) 1603.

[11] Z. Hong, C. Liang, R. Li, W. Li, W. Li, D. Zhao, D. Fan, D. Wang, B. Chu, F. Zang, L. Hong and S. Lee, Adv. Mater. 16 (2001) 1241.

[12] M.Fakhfakh, H.Turki, S. Fery-Forgues and R.El-Gharbi, J. Dyes and Pigments 84 (2010) 108-113.

[13] M.McGehee, T. Bergstedt, C. Zhang, A. Saab, M.O'Regem, G. Bazan, V. Srdanov and A. Heeger, Adv. Mater. 11 (1999) 1349.

[14] G. Yu, Y. Liu, X. Wu, D. Zhu, H. Li, L. Jin and M. Wang, Chem. Mater. 12 (2000) 2537.

[15] M. Sun, H. Xin, K. Wang, Y. Zhang, L. Jin and C. Huang, Chem. Commun. 6 (2003) 702.

[16] F. Liang, Q. Zhou, Y. Cheng, L. Wang, D. Ma, X. Jing and F. Wang, Chem. Mater. 15 (2003) 1935.

[17] P. Sun, J. Duan, H. Shih and C. Cheng, Appl. Phys. Lett. 81 (2002) 792.

[18] V. Bekiari and P. Lianos, Adv. Mater. 12 (2000) 1603.

[19] M. Wang, Z. Yang, Z. Liu, Y. LI, T. Li, M. Yan and X. Cheng, J. Coord. Chem. 65 (2012) 3805.

[20] L. Thunus and R. Lejeune, Coord. Chem. Rev. 184 (1999) 125.

[21] C. Cutler, C. Smith, G. Ehrhardt, T. Tyler, S. Jurisson and E. Deutsch, Cancer Biother. Radiopharm. 15 (2000) 531.

[22] Z. Li, M. Xue, H. Yao, H. Sun, Y. Zhang and Q. Shen, J. Organomet. Chem. 713 (2012) 27.

[23] T. Yang and W. Qin, Spectrochim. Acta Part A 67 (2007) 568.

[24] M. Wang, Z. Yang, Y. Li and H. Li, J. Coord. Chem. 64 (2011) 2974

[25] A.Manvar, A.Malde, J.Verma, V.Virsodia, A. Mishra, K.Upadhyay, H. Acharya, E.Coutinho and A. Shah, European Journal of Medicinal Chemistry 43 (2008) 2395 -2403 .

[26] A.Manvar, A.Malde, J.Verma , V.Virsodia, A. Mishra, K.Upadhyay, H. Acharya, E.Coutinho and A. Shah, Indian Journal of Chemistry 50B (2011) 315-320

[27] B. El-Sayed, S. Shaaban, M. Sallam, and A. Emara, Journal of Materials Science Letters 15(1996) 883885 . 
[28] W. Greary, Coord. Chem. Rev. 7 (1971) 81

[29] A. Ajlouni, Z. Taha, K. Al-Hassan and A. AbuAnzeh, J. Lumin. 132 (2012) 1357-1360.

[30] G. Leniec, S.Kaczmarek, J. Typek, B. Kołodziej, E. Grech and W. Schilf, J. Phys.Condens. Matter 18 (2006) 9871-9880.

[31] S.Kaczmarek and G. Leniec, J. Non-Cryst. Solids 355 (2009) 1289-1438

[32] L. Lekha , K. Kanmani Raja , G. Rajagopal and D. Easwaramoorthy, J. of Mol. Str. 1056-1057 (2014) 307-313.

[33] V. Mutalik and M. Phaniband, J. Chem. Pharm. Res.,
3(2) (2011) 313-330

[34] C. Görller-Walrand and K. Binnemans, Handbook on the Physics Chemistry of Rare Earths, North-Holland Publishers, Amsterdam, 25 (1998). 101.

[35] N. Raman, K. Pothiraj, T. Baskaran, J. Mol. Struct. 1000 (2011) 135-144.

[36] P.R. Shakya, A.K. Singh, T.R. Rao, Spectrochim. Acta A 79 (2011) 1654-1659

[37] L. Ismail, M. Antonious, B. El-Sayed and M. AbdelMottaleb, J. chem. Sci. 107 (1995) 735-742.

[38] M.Attia, J. of SpectrochemicaActa part A 74 (2009) 972-976. 